\title{
Anomalous Hardening of Submicron Porous Silver at High Strain Rates
}

\author{
Alan F Jankowski ${ }^{1} \&$ Tanvir Ahmed ${ }^{2}$ \\ ${ }^{1}$ Department of Mechanical Engineering, Texas Tech University, USA \\ ${ }^{2}$ University of Texas - El Paso, United States, 500 West University Avenue, El Paso, USA \\ Correspondence: Alan F Jankowski, Department of Mechanical Engineering, Texas Tech University, USA. \\ E-mail: alan.jankowski@ttu.edu
}

Received: April 6, 2012 Accepted: April 23, 2012 Online Published: June 11, 2012

doi:10.5539/jmsr.v1n3p76

URL: http://dx.doi.org/10.5539/jmsr.v1n3p76

\begin{abstract}
Microscratch hardness measurements were conducted on porous silver membranes using a sphero-conical Rockwell indenter over a strain rate range of $10^{-1}-10^{+4} \mathrm{~s}^{-1}$. At high strain rates, the porous silver has a strain-rate sensitivity of hardness that is enhanced in comparison to its dense counterpart. The enhancement is found to increase for strain rates greater than $10^{+2} \mathrm{~s}^{-1}$ wherein strain rate exponents are measured as high as 0.25 . The increase appears attributable to the free volume available for deformation within the porous structure. This result represents up to a five-fold increase in the exponent value in comparison to tensile tests conducted at strain rates less than $10^{-1} \mathrm{~s}^{-1}$.
\end{abstract}

Keywords: porous metals, strain-rate sensitivity, microscratch hardness

\section{Introduction}

Most materials are known to have different strength values at different strain rates $(\dot{\varepsilon})$, i.e. materials often exhibit some level of strain-rate sensitivity. For example, the tensile strength of rolled nickel foil is observed (Humphrey \& Jankowski, 2011) to increase from 360 to $445 \mathrm{MPa}$ as the strain rate increases from $10^{-3}$ to $10^{-1} \mathrm{~s}^{-1}$. Many testing methods are available as, for example, tension (Emery \& Povirk, 2003a, 2003b; Jankowski et al., 2006; Wang et al., 2007; Nyakiti et al., 2008; Ahmed \& Jankowski, 2009) and compression (Volkert et al., 2006; Banno et al., 2007; Hakamada \& Mabuchi, 2007; Lee et al., 2008) with typical $\varepsilon$ of $10^{-4}-10^{-1} \mathrm{~s}^{-1}$. In addition, microindentation (Wilsea et al., 1975; Fleck et al., 1992; Andrews et al., 2001; Liu et al., 2003; Ramamurty \& Kumaran, 2004) and nanoindentation (Volinsky et al., 2003; Toivola et al., 2004; Chen et al., 2006; Xiang et al., 2006) provide alternate methods of testing across ranges in specimen size. The synthesis and mechanical performance of porous membranes and coatings (Gibson, 2000; Jankowski \& Hayes, 2003; Morse et al., 2000) is of interest for a wide variety of applications such as catalytic surfaces and interconnects for fuel cells, energy absorbing materials, etc. The tensile properties of porous silver membranes are seen (Ahmed \& Jankowski, 2009, 2012) to be rate dependent as well at $\dot{\varepsilon}$ below $10^{-1} \mathrm{~s}^{-1}$, and to progressively stiffen with deformation. In general, as the free volume of the pores decreases (in the initial condition or) through progressive deformation, it was reported (Ahmed \& Jankowski, 2009, 2012) that the porous membrane strengthens with strain rate and rapidly stiffens.

In this study we explore the strain rate dependence of strength using an innovative use of tribomechanical testing, i.e. the microscratch indentation test, for the direct measurement of scratch hardness over the $10^{-1}-10^{+3} \mathrm{~s}^{-1} \mathrm{strain}$ rate range. In comparison, for tensile tests, the presence of internal defects in the test material often leads to premature failure through stress concentration effects where a significant strength variation can result. As such, the hydrostatic loading coupled with flow stress enables scratch indentation testing to be utilized where brittle failure would otherwise be encountered during tensile testing at high strain-rates.

The purpose, at present, is to investigate the behavior of porous metals in a dynamic condition wherein a transition from (i) athermal long-range barriers as alloying elemental contents in strain-rate region I (at $\dot{\varepsilon}<10^{-1}$ $\mathrm{s}^{-1}$ ) to (ii) short-range barriers through dislocation-based mediated deformation in region II (at $10^{-1}<\dot{\varepsilon}<10^{+3} \mathrm{~s}^{-1}$ ) to (iii) phonon-drag mitigated behavior, i.e. the drag resisting velocities of dislocations, in region III $\left(\dot{\varepsilon}^{\prime}>10^{+3} \mathrm{~s}^{-1}\right)$ becomes evident as reported (Freund \& Hutchinson, 1985, 1988; Regazzoni et al., 1987; Armstrong \& Zerilli, 
1988; Ahmed \& Jankowski, 2009) for dense metals and alloys. The microscratch indentation method has proven valuable to study the behavior of dense nanocrystalline metals as Ni (Humphrey \& Jankowski, 2011) and alloys as $\mathrm{Au}(\mathrm{Cu})$ (Nyakiti et al., 2008; Nyakiti \& Jankowski, 2010; Jankowski \& Nyakiti, 2010) wherein strength and the transition between strain-rate regions I-II and II-III is seen to be dependent upon both grain size and grain boundary structure for operational ranges of active deformation mechanisms.

\section{Experimental Procedures}

\subsection{Materials}

Silver membranes of $>0.9995$ purity having a nominal pore size $\left(h_{p}\right)$ of $0.22,0.45,0.80$ and $3.0 \mu \mathrm{m}$ and a thickness range of $60-80 \mu \mathrm{m}$ are used for the test sample as procured from General Electric Osmonics. This range of pore size provides extends from the micron- to the nano-scale wherein the effect of open volume can be further explored for strain rate effects on strengthening. The membrane density $(\rho)$ is determined from microbalance measurements of membrane weight and volume. The porosity $(p)$ is computed as the ratio of the membrane density $(\rho)$ to the density of pure silver $\left(\rho_{A g}\right)$ as

$$
p=1-\rho \cdot\left(\rho_{A g}\right)^{-1}
$$

where $\rho_{A g}$ has a nominal value of $10.5 \mathrm{gm} \cdot \mathrm{cm}^{-3}$ (Trent et al., 1982) at $20{ }^{\circ} \mathrm{C}$. The membranes are characterized using the secondary-electron imaging mode of a Hitachi S-4300 scanning electron microscope (SEM) to accentuate topological features. The dense silver foil with 0.9995 purity and $50 \mu \mathrm{m}$ nominal thickness as procured from SurePure Chemetals is characterized by Bragg x-ray diffraction (XRD) in the $\theta / 2 \theta$ mode using a Rigaku Miniflex II diffractometer as operated with $30 \mathrm{kV}-15 \mathrm{~mA} \mathrm{Cu} k_{\alpha}$ x-rays to determine the crystalline orientation of the grains within the foil.

\subsection{Microscratch Test}

The micro-scratch experiments are conducted using a Universal Micro-nano-materials Tester (UMNT) manufactured by Bruker-CETR (Center for Tribology). The indentation module and specimen table are mounted on a mechanical vibration isolation table. A sphero-conical Rockwell diamond indenter is used with a $12.5 \mu \mathrm{m}$ radius and $60^{\circ}$ included cone angle. The membranes and dense foil considered for analysis in the present study are mounted in cross-section within an epoxy mount to enhance specimen stability during the microscratch measurements. A nominal $10 \mathrm{~g}$ load $(98 \mathrm{mN})$ is applied normal to the sample surface while the y-stage of the UMNT moves in one direction to create the scratch indentation. The scratch velocity $(v)$ is varied over a nominal range of $0.01-10 \mathrm{~mm} \cdot \mathrm{s}^{-1}$ to induce different strain-rates $(\hat{\varepsilon})$. The microscratch profiles are imaged using an optical microscope to measure the scratch width $(w)$ that has a typical range of $15-25 \mu \mathrm{m}$ as dependent upon $\dot{\varepsilon}$. Here, $w$ is measured perpendicular to the scratch direction where an average value is obtained over the full length of the microscratch.

\section{Results}

\subsection{Computational Method}

The scratch hardness $\left(H_{s}\right)$ is computed conventionally by dividing the normal load $(N)$ by the lead-half projection of the tip in the scratch direction as

$$
H_{s}=c \cdot N \cdot w^{-2}
$$

where the constant $c$ gives the tip shape contribution that equals $8 / \pi$ for a sphero-conical indenter at $w$ less than the tip diameter. For this indenter-tip shape condition (Tabor, 1970) the load introduces work hardening into the indentation process that can be approximated to a plastic strain of $8 \%$. The final scratch width that represents the shearing of the material in plastic deformation is used to formulate (Jankowski \& Nyakiti, 2010; Humphrey \& Jankowski, 2011) an expression for the strain rate as

$$
\dot{\varepsilon}=v \cdot w^{-1}
$$

The eqn. (3) formulation proves most useful since measurement of the actual depth of the scratch indentation is uncertain due to elastic effects and the displacement (hence, strain) rate normal to the surface is variable.

The strain-rate sensitivity exponent $(m)$ to the classic power law representation of the strength $(\sigma)$ at the onset of plastic deformation as function of strain rate is formulated from the Dorn equation. In this case, the scratch hardness is used as a measure (Jankowski \& Nyakiti, 2010) of strength providing a formulation for the strain rate exponent $(m)$ that is expressed as

$$
m=\delta \ln H_{s} \cdot \delta(\ln \dot{\varepsilon})^{-1}
$$


The values for $m$ from the scratch indentation tests computed using eqn. (4) can then be compared directly with those $m$ values obtained by conventional tensile and compression tests.

\subsection{Morphology and Structure}

The average length of a constituent filament $\left(h_{f}\right)$ intrinsic to each porous structural network was measured (Ahmed \& Jankowski, 2009) at each nominal pore size $\left(h_{p}\right)$. The results are listed in Table 1 along with the porosity $(p)$ as computed from eqn. (1).

The morphology of the porous membranes is seen in the SEM plan view images of Figure 1. The porous membranes have an average grain size $\left(h_{g}\right)$ of $2.5 \pm 0.2 \mu \mathrm{m}$ as based on measurement (Ahmed \& Jankowski, 2009) of the width to the bamboo-like structure to each filament. The results (Ahmed \& Jankowski, 2009) of a cross-sectioning study and the tensile test behavior of the porous silver membranes indicate that the structures shown in plan view are representative of the cross-section structure as well.

Table 1 . The strain rate sensitivity exponent $(\boldsymbol{m})$ of porous membranes and dense silver

\begin{tabular}{cccccc}
\hline pore size & porosity & filament length & \multicolumn{2}{c}{ strain-rate sensitivity exponent $\boldsymbol{m}$} \\
$\boldsymbol{h}_{\boldsymbol{p}}(\mu \mathrm{m})$ & $\boldsymbol{p}$ & $\boldsymbol{h}_{\boldsymbol{f}}(\mu \mathrm{m})$ & region I & region II & region II-III \\
\hline 3.00 & $0.50 \pm 0.04$ & $5.9 \pm 3.6$ & $0.029 \pm 0.008$ & $0.031 \pm 0.011$ & $0.252 \pm 0.008$ \\
0.80 & $0.48 \pm 0.02$ & $3.8 \pm 1.5$ & $0.050 \pm 0.007$ & $0.007 \pm 0.006$ & $0.200 \pm 0.016$ \\
0.45 & $0.34 \pm 0.02$ & $8.1 \pm 5.6$ & $0.025 \pm 0.012$ & $0.074 \pm 0.007$ & $0.132 \pm 0.028$ \\
0.22 & $0.26 \pm 0.01$ & $6.1 \pm 2.5$ & $0.035 \pm 0.002$ & $0.025 \pm 0.018$ & $0.132 \pm 0.016$ \\
dense & 0 & - & $0.014 \pm 0.002$ & $0.007 \pm 0.006$ & $0.095 \pm 0.015$ \\
\hline
\end{tabular}

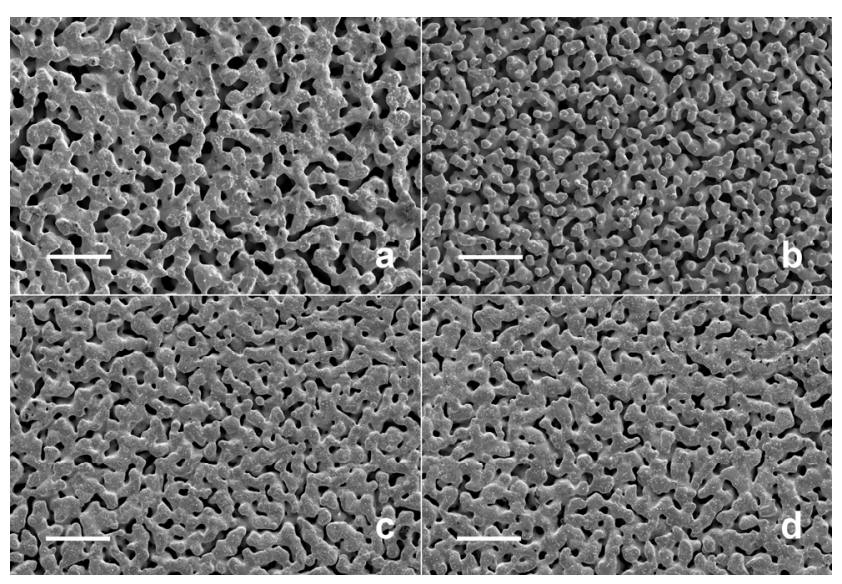

Figure 1. The scanning-electron micrographs are shown for the porous silver membranes with (a) 3.0, (b) 0.85 , (c) 0.45 , and (d) $0.22 \mu \mathrm{m}$ pore size (the marker length equals $20 \mu \mathrm{m}$ )

The XRD scan in Figure 2 provides an approximate measurement of the grain size as $0.3-0.4 \mu \mathrm{m}$ for the dense silver foil as computed from the full-width at half-maximum intensity of the (220) reflection using the Debye-Scherer formulation as corrected for instrument broadening. 


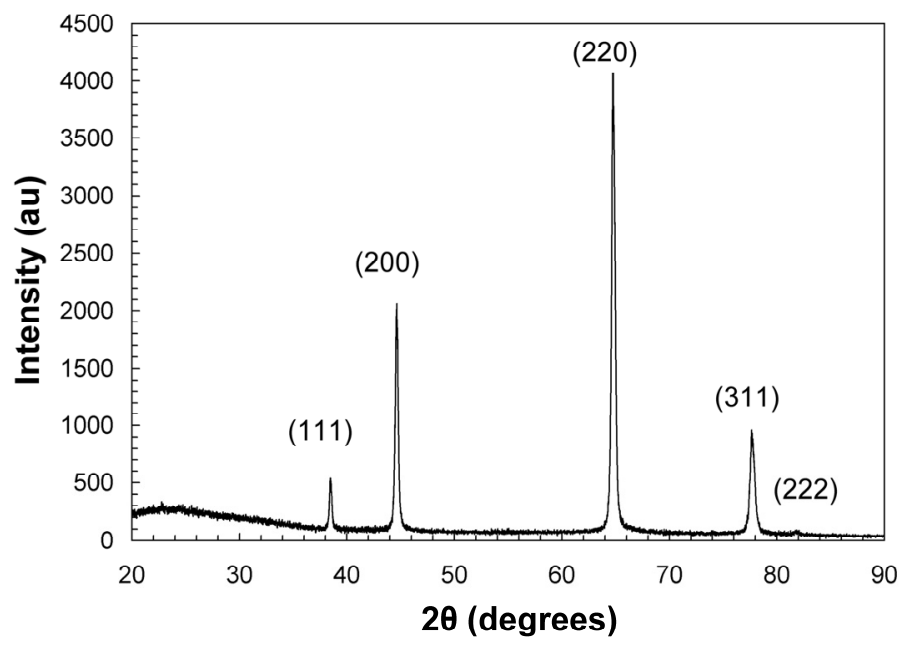

Figure 2. A x-ray diffraction scan, taken in the $\theta / 2 \theta$ mode using $30 \mathrm{kV}-15 \mathrm{~mA} \mathrm{Cu} k_{\alpha} \mathrm{x}$-rays, reveals the variation of reflected intensity with $2 \theta$ position from the dense silver foil

\subsection{Microscratch Hardness}

The microscratch indentation hardness $\left(H_{s}\right)$ values computed from measurements of the scratch width using eqn. (2) are plotted as a function of the strain rate as computed using eqn. (3). In general, it is seen that the $H_{s}$ increases over a $10^{-1}-10^{+3} \mathrm{~s}^{-1}$ strain rate range for all samples. There are two distinct curvilinear regions for each porous membrane sample (and the dense foil) that are visible in the Figure 3 data. A best fit, in accordance with region II-type behavior as generally seen for $\dot{\varepsilon}<10^{+2} \mathrm{~s}^{-1}$, is made to compute the strain-rate sensitivity exponent $(m)$ from eqn. (4) that maximizes the correlation coefficient $\left(R^{2}\right)$, i.e. minimizes the curve-fit variance. These $m$-values for region II are listed in Table 1. A transition in the trend of $H_{s}$ values is seen with increasing strain rate, i.e. for $\dot{\varepsilon}>10^{+2}-10^{+3} \mathrm{~s}^{-1}$, as evidenced by a rapid rise in the scratch hardness. The scratch hardness behavior in this range of increased strain rates may be described as a transition into region III where region III behavior is found typically for $\dot{\varepsilon}>10^{+3} \mathrm{~s}^{-1}$. The values computed for $m$ that correspond with this region II-III transition are listed in Table 1. The transition occurs with increasing strain rate and a reduction in pore size.

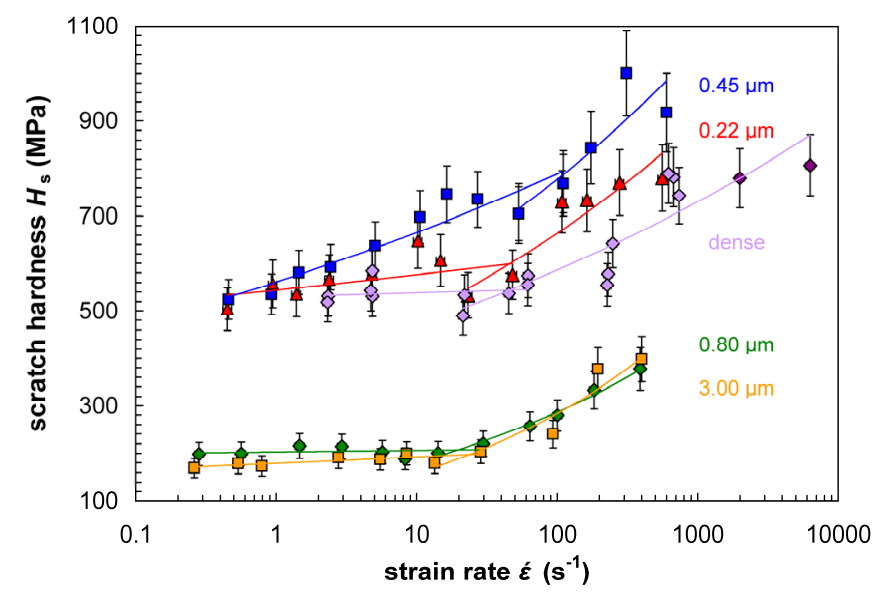

Figure 3. The variation of scratch hardness $\left(\mathrm{H}_{\mathrm{s}}\right)$ with strain rate $(\hat{\varepsilon})$ is plotted as a function of the nominal pore size $\left(h_{p}\right)$ for the porous membranes and dense silver-foil samples

The $m$-values from tensile testing results in region I that were reported previously (Ahmed \& Jankowski, 2009) are listed in Table 1. It is seen that the $m$-values for region I are consistent with the new region II values from the microscratch tests as expected based on operative deformation mechanism. That is, the $m$-values are $0.025-0.050$ 
for tension tests and 0.01-0.07 for the microscratch tests. This example for a region I-to-II comparison clearly illustrates a valid use of microscratch method for measuring $m$-values at higher strain rates. In addition, the $H_{s}$-values for dense silver show $m$-values that are similar from the 0.014 in tension (for region I) to 0.01 by microscratch (in region II). Similarly, an $m$-value of 0.025 is reported (Hu \& Hong, 2011) for compression tests in Regions I-to-II over a strain rate range of $10^{-6}$ to $10^{-1} \mathrm{~s}^{-1}$.

Of significance is that the $m$-values rise significantly to $0.13-0.25$ as the strain rate increases towards region III as evidenced by the microscratch measurements in the transition region II-III listed in Table 1. Also, consistent with the microscratch data in region II-III are the two data points plotted at $2.0 \cdot 10^{+3}$ and $6.3 \cdot 10^{+3} \mathrm{~s}^{-1}$ for dense silver. These high strain-rate $H_{s}$-values for $\dot{\varepsilon}>10^{+3} \mathrm{~s}^{-1}$ correspond with a scratch hardness computed by multiplying a factor of three (Tabor, 1970) times the shear-type flow-strength made using split Hopkinson pressure bar measurements (Hu \& Hong, 2011) of dense silver with similar grain size. The $m$-values listed in Table 1 increase in the transition region II-III as a function of an increase in the pore size and porosity.

\section{Analysis and Discussion}

An evaluation of the grain size $\left(h_{g}\right)$ effect through the Hall-Petch relationship on the extent of strengthening can be made using values reported for the strengthening coefficient $\left(k_{\sigma}\right)$ (Aldrich \& Armstrong, 1970) as 169 $\mathrm{MPa} \cdot \mu \mathrm{m}^{-1 / 2}$ and the friction stress $\left(\sigma_{o}\right)$ (Gubicza et al., 2008) as $30 \mathrm{MPa}$ for uniaxial loading at a strain rate of $\sim 10^{-4} \mathrm{~s}^{-1}$. The grain size that corresponds with reported yield strengths $\left(\sigma_{y}\right)$ as computed for dense silver samples are: $0.32 \mu \mathrm{m}$ (versus $0.25 \mu \mathrm{m}$ reported) for a $330 \mathrm{MPa}$ equal-channel angular processed material (Gubicza et al., 2008); $14 \mu \mathrm{m}$ for a $75 \mathrm{MPa}$ coarse grain silver (Hu \& Hong, 2011); $1 \mu \mathrm{m}$ (versus $50 \mathrm{~nm}$ reported) for a $200 \mathrm{MPa}$ fine grain silver (Hu \& Hong, 2011) in compression; and $0.47 \mu \mathrm{m}$ for the $275 \mathrm{MPa}$ tensile strength of the dense foils used in this study. The compression test measurements should be comparable to the tensile test values. The $0.47 \mu \mathrm{m}$ grain size value for the dense silver of this study is consistent with the XRD measurement from Figure 2. The $275 \mathrm{MPa}$ tensile strength of the dense silver sample can be converted to an equivalent scratch indentation hardness value of $\sim 475 \mathrm{MPa}$ for comparison with the Figure 3 results. The strength-to-hardness conversion equivalence is determined using a multiplication factor of $\sqrt{3}$ from the von Mises criteria as presented in detail elsewhere (Humphrey \& Jankowski, 2011). The $475 \mathrm{MPa}$ scratch hardness estimate from the tensile strength value is consistent with the $H_{s}$ values within region II of Figure 3.

For both the microscratch and tensile tests of porous silver membranes it can be postulated that the change in deformation mechanism from region I to II occurs with the dislocation based strengthening. Similar behavior is observed (Harding, 1987; Armstrong \& Zerilli, 1988; Schwaiger et al., 2003; Armstrong \& Walley, 2008) for other metals and alloys at high strain-rates where it is reported that the transition between regions of operative deformation mechanisms can occur at different strain rates as dependent upon material composition and structure. The porous silver membranes evidence a transition into region III at $10^{+1}-10^{+2} \mathrm{~s}^{-1}$ strain rates. In general, the observation is made that with an increase in porosity from the fully dense state to the most porous sample, a significant increase in the strain-rate sensitivity is seen with the region II-III transition.

Similar increases in the strain-rate sensitivity of strength have been reported for porous materials as strain rates increase from region I into III. For example (Mukai et al., 1999; Paul \& Ramamurty, 2000; Ramachandra et al., 2003; Sudheer et al., 2003), consider the high speed impact tests (which involve both crushing and tearing forces) and the compression tests of closed-cell aluminum foams with large cell sizes on the order of $\sim 5 \mathrm{~mm}$. Experimental results show an increase in $m$ by a factor of almost three from 0.017 for $\dot{\varepsilon}<10^{-2} \mathrm{~s}^{-1}$ to 0.042 for $10^{-1}<\dot{\varepsilon}<10^{+3} \mathrm{~s}^{-1}$. Although the scale of the increase in $m$ is pronounced, the magnitude is smaller as could be anticipated for pore sizes that are one-thousand times greater than for membranes in the present study.

This real phenomenon of a strength increase into region II-III may be attributable to the progressive increase in free-volume that accompanies porous structures with longer filaments (Ahmed \& Jankowski, 2012) that are accessible to extreme deformation as seen in the Figure 3 mechanical behavior of the $0.45 \mu \mathrm{m}$ porous membrane. A concept is proposed that the free-volume for deformation associated with the membrane porosity enables an ease in realignment of the filaments, which increases relative strength and stiffness under dynamic loading conditions such as induced by high strain-rates. At these higher strain rates, phenomena as dynamic recrystallization may slow the increase in scratch hardness of dense silver. With the micro-scratch testing of the porous silver specimens, only the region II-III transition was accessible.

Even higher strain-rate instrumentation development will be necessary for microscratch indentation testing to fully access the region III behavior. At the high strain rates found in region III, molecular dynamics simulations (Erhart et al., 2005) of shock loading to porous single-crystal filamentary samples has shown the formation of a 
nanocrystalline grain structure. This result is attributed to localized plastic deformation induced by the presence of voids. The onset of a nanocrystalline structure would, in turn, rapidly strengthen the porous material.

\section{Conclusions}

An experimental method to investigate the strain-rate sensitivity $(m)$ of strength in dense and porous materials at higher strain-rates $(\dot{\varepsilon})$ is microscratch indentation testing. Porous membranes and a dense foil of $>0.9995$ pure silver are measured over a $10^{-1}-10^{+3} \mathrm{~s}^{-1}$ strain rate range. Below $\sim 10^{+2} \mathrm{~s}^{-1}, m$-values of $0.01-0.07$ are measured that are consistent with tensile test results which evidence continuity in deformation mechanism reported for region I and II type behavior as typified by solution effects and dislocation structure contributions to strengthening. A significant increase in the scratch hardness $\left(H_{s}\right)$ occurs at strain-rates greater than $10^{+2} \mathrm{~s}^{-1}$ as the pore size decreases. In addition, a significant increase of the strain-rate sensitivity exponent $(\mathrm{m})$ of scratch hardness $\left(H_{s}\right)$ occurs at $\dot{\varepsilon}>10^{+2} \mathrm{~s}^{-1}$ that is consistent with the trends for high-velocity indentation testing of porous metals. An $m$-value of 0.09 for dense silver is exceeded by all of the porous structures for $\dot{\varepsilon}>10^{+2} \mathrm{~s}^{-1}$ wherein a progressive increase in membrane porosity $(p)$ and pore size $\left(h_{p}\right)$ now produces increased $m$-values as high as 0.25 . A proposed explanation is that the free-volume for deformation associated with the membrane porosity enables an ease in realignment of the filament structure which increases the relative hardness under dynamic loading conditions such as induced by high strain-rates under microscratch indentation tests.

\section{References}

Ahmed, H. S. T., \& Jankowski, A. F. (2009). The mechanical strength of submicron porous silver foils. Surf. Coatings Technol., 204, 1026-1029. http://dx.doi.org/10.1016/j.surfcoat.2009.05.040

Ahmed, H. S. T., \& Jankowski, A. F. (2012). Stiffening of submicron porous silver membranes under tensile deformation. Mater. Sci. Eng. B, 177, 43-47. http://dx.doi.org/10.1016/j.mseb.2011.09.028

Aldrich, J. W., \& Armstrong, R. W. (1970). The grain size dependence of the yield, flow and fracture stress of commercial purity silver. Metall. Trans., 1, 2547-2550

Andrews, E. W., Gioux, G., Onck, P., \& Gibson, L. J. (2001). Size effects in ductile cellular solids. Part II: experimental results. International J. Mechanical Sciences, 43, 701-713.

Armstrong, R. W., \& Walley, S. M. (2008). High strain rate properties of metals and alloys. International Materials Reviews, 53, 105-128. http://dx.doi.org/10.1179/174328008X277795

Armstrong, R. W., \& Zerilli, F. J. (1988). Dislocation mechanics based analysis of material dynamics behavior. $J$. Physique Coll., 49C3, 529-534

Banno, T., Li, Y., Wen, C., \& Yamada, Y. (2007). Mechanical Properties of Micro-Porous Metals Produced by Space-Holding Sintering. Advanced Materials Research, 29-30, 75-78

Chen, X., Xiang, Y., \& Vlassak, J. J. (2006). Novel technique for measuring the mechanical properties of porous materials by nanoindentation. J. Materials Research, 21, 715-724

Emery, R. D., \& Povirk, G. L. (2003a). Tensile behavior of free standing gold films - Part 1 coarse grained films Acta Materialia, 51, 2067-78. http://dx.doi.org/10.1016/S1359-6454(03)00006-5

Emery, R. D., \& Povirk, G. L. (2003b). Tensile behavior of free standing gold films - Part 2 fine grained films Acta Materialia, 51, 2079-87. http://dx.doi.org/10.1016/S1359-6454(03)00007-7

Erhart, P., Bringa, E. M., Kumar, M., \& Albe, K. (2005). Atomistic mechanism of shock-induced void collapse in nanoporous metals. Phys. Rev. B, 72, 052104-1-4. http://dx.doi.org/10.1103/PhysRevB.72.052104

Fleck, N. A., Otoyo, H., \& Needleman, A. (1992). Indentation of porous solids. International J. Solids and Structures, 29, 1613-1636.

Freund, L. B., \& Hutchinson, J. W. (1985). High strain-rate crack growth in rate-dependent plastic solids. J. Mech. Phys. Solids, 33, 169-191.

Gibson, L. J. (2000). Mechanical behavior of metallic foams. Annual Review of Materials Science, 30, 191-227

Gubicza, J., Chinh, H. Q., Lábár, J. L., Hegedűs, Z., Xu, C., \& Langdon, T. G. (2008). Microstructure and yield $\begin{array}{lllll}\text { strength of severely deformed silver. Scripta Mater., } & \text { 58, } & \text { 775-778. }\end{array}$ http://dx.doi.org/10.1016/j.scriptamat.2007.12.028

Hakamada, M., \& Mabuchi, M. (2007) Mechanical strength of nanoporous gold fabricated by dealloying. Scripta Materialia, 56, 1003-1006. http://dx.doi.org/10.1016/j.scriptamat.2007.01.046 
Harding, J. (1987). The effect of high strain rate on material properties, in Materials at High Strain Rates. T. Z. Blazynsky (ed.) Elsevier Applied Science, Amsterdam, 133-151.

Hu, G., \& Hong, Z. (2011) Mechanical Properties of Bulk Nanocrystalline Silver-Using Compression Tests. Adv. Mater. Res., 152-153, 1313-1316. http://dx.doi.org/10.4028/www.scientific.net/AMR.152-153.1313

Humphrey, R. T, \& Jankowski, A. F. (2011). Strain-rate sensitivity of strength in macro-to-micro-to-nano crystalline nickel. Surf. Coatings Technol., 206, 1845-1849. http://dx.doi.org/10.1016/j.surfcoat.2011.08.010

Jankowski, A. F., \& Hayes, J. P. (2003). Sputter deposition of a sponge-like morphology in metal coatings. $J$. Vacuum Sci. Technol. A, 21, 422-425.

Jankowski, A. F., \& Nyakiti, L. O. (2010). Anomalies in Hall-Petch strengthening for nanocrystalline $\mathrm{Au}-\mathrm{Cu}$ alloys $<10 \quad \mathrm{~nm}$ grain size. Surf. Coatings Technol., 205, 1398-1402. http://dx.doi.org/10.1016/j.surfcoat.2010.07.106

Jankowski, A. F., Saw, C. K., \& Hayes, J. P. (2006). The thermal stability of nanocrystalline $\mathrm{Au}-\mathrm{Cu}$ alloys. Thin Solid Films, 515, 1152-1156. http://dx.doi.org/10.1016/j.tsf.2006.07.167

Lee, M. H., Kim, K. B., Han, J., Eckert, J., \& Sordelet, D. J. (2008). High strength porous Ti-6Al-4V foams synthesized by solid state powder processing, J. Phys. D: Appl. Phys., 41, 105404-1-5. http://dx.doi.org/10.1088/0022-3727/41/10/105404

Liu, Z., Chuah, C. S. L., \& Scanlon, M. G. (2003). Compressive elastic modulus and its relationship to the structure of a hydrated starch foam. Acta Materialia, 51, 365-371. http://dx.doi.org/10.1016/S1359-6454(02)00400-7

Morse, J. D., Jankowski, A. F. Graff, R. T., \& Hayes, J. P. (2000). Novel proton exchange membrane thin-film fuel cell for microscale energy conversion. J. Vacuum Sci. Technol. A, 18, 2003-2005.

Mukai, T., Kanahashi, H., Miyoshi, Mabuchi, M., Nieh, T. G., \& Higashi, K. (1999). Experimental study of energy absorption in a close-celled aluminum foam under dynamic loading. Scripta Mater., 40, 921-927.

Nyakiti, L. O., \& Jankowski, A. F. (2010) Characterization of Strain-Rate Sensitivity and Grain Boundary Structure in Nanocrystalline Gold-Copper Alloys. Metal. Mater. Trans. A, 41, 838-848. http://dx.doi.org/10.1007/s11661-009-9996-9

Nyakiti, L. O., Chaudhuri, J., \& Jankowski, A. F. (2008). High-resolution electron microscopy characterization of nanocrystalline grain boundaries in gold-copper alloys. Thin Solid Films, 517, 1182-1185. http://dx.doi.org/10.1016/j.tsf.2008.06.007

Paul, A., \& Ramamurty, U. (2000). Strain rate sensitivity of a closed-cell aluminum foam. Materials Science and Engineering A, 281, 1-7.

Ramachandra, S., Sudheer, Kumar, P., \& Ramamurty, U. (2003). Impact energy absorption in an Al foam at low velocities. Scripta Mater., 49, 741-745. http://dx.doi.org/10.1016/S1359-6462(03)00431-7

Ramamurty, U., \& Kumaran, M. C. (2004). Mechanical property extraction through conical indentation of a closed-cell aluminum foam. Acta Materialia, 52, 181-189. http://dx.doi.org/10.1016/j.actamat.2003.09.004

Regazzoni, G., Kocks, U. F., \& Follansbee, P. S. (1987). Dislocation kinetics at high strain rates. Acta Metall., $35,2865-2875$

Schwaiger, R., Moser, B., Dao, M., Chollacoop, N., \& Suresh, S. (2003). Some critical experiments on the strain-rate sensitivity of nanocrystalline nickel. Acta Materialia, 51, 5159-5172

Sudheer, Kumar, P., Ramachandra, S., Ramamurty, U. (2003). Effect of displacement-rate on the indentation behavior of an aluminum foam. Mater. Sci. Eng. A, 347, 330-337

Tabor, D. (1970). The hardness of solids. Review of Physics in Technology, 1, 145-179.

Toivola, Y., Stein, A., \& Cook, R. F. (2004). Depth-sensing response of ordered silica foam. J. Materials Research 19, 260-271.

Trent, H. M., Stone, D. E., \& Lindsay, R. B. (1982). "Density of Solids" in Ch. 2 of American Institute of Physics Handbook (3rd ed.). D. E. Gray (ed.). New York: McGraw-Hill. pp. 19-37.

Volinsky, A. A., Vella, J. B., \& Gerberich, W. W. (2003). Fracture toughness, adhesion and mechanical properties of low-K dielectric thin films measured by nanoindentation. Thin Solid Films, 429, 201. 
Volkert, C. A., Lilleodden, E. T., Kramer, D., \& Weissmuller, J. (2006). Approaching the theoretical strength in nanoporous Au. Appl. Phys. Lett., 89, 061920-1-3. http://dx.doi.org/10.1063/1.2240109

Wang, Y. M., Jankowski, A. F., \& Hamza, A. V. (2007). Strength and thermal stability of nanocrystalline gold alloys. Scripta Materialia, 57, 301-304. http://dx.doi.org/10.1016/j.scriptamat.2007.04.046

Wilsea, M., Johnson, K. L., \& Ashby, M. F. (1975). Indentation of foamed plastics. International J. Mechanical Sciences, 17, 457-460.

Xiang, Y., Chen, X., Tsui, T. Y., Jang, J. I., \& Vlassak, J. J. (2006). Mechanical properties of porous and dense low-K dielectric films measured by means of nanoindentation and the plane-strain bulge test technique. $J$. Materials Research, 21, 386-395. 